\title{
Notes ON SOME ASPECTS OF THE TAXONOMY OF "GENERATIONS" OF RIGHTS
}

MARK TUSHNET $^{\dagger}$

\section{A DOSSIER ON TAXONOMY OF GENERATION OF RIGHTS}

KEYWORDS: Fundamental Rights; Varieties of Constitutionalism; Generations of Rights.

PAlavRAS-ChaVe: Direitos Fundamentais; Variedades de Constitucionalismo; Gerações de Direitos.

\footnotetext{
${ }^{\dagger}$ William Nelson Cromwell Professor of Law, Harvard Law School. These comments are part of my initial effort to develop a larger framework for analyzing what I call varieties of constitutionalism.
} 
Students of national constitutions often distinguish among constitutions that embrace (only) first generation rights and those that embrace second and third generation rights as well. The language of "generations" suggests both a historical sequence and a genetic relationship. Other metaphors are that second and third generation rights "deepen" or "expand" constitutional commitments to human rights, the latter understood as a comprehensive category. These ways of talking about the generations of rights suggest that each generation of rights is compatible with the prior one(s). In the following brief comments I explore the possibility that there are ineliminable conflicts between second and third generation rights and first generation rights. If there are such conflicts, perhaps we should speak of second and third generation rights as sometimes displacing or overriding first generation rights (or third generation rights displacing second generation ones), and that it might be profitable to examine the circumstances under which such displacement properly occurs.

The first task, of course, is to describe the different generations of rights. Conventionally, the first generation rights are classical liberal rights to life, liberty, and property, equality with respect to those rights, and rights to equal participation in civic life, including, importantly, equal participation in the institutions of democratic self-governance. As I have suggested elsewhere, all real constitutional systems fall short in the realization of first generation rights, and in all constitutional systems there are reasonable disagreements about the precise content or, as I prefer to call it, the specification of abstract rights in more concrete circumstances. ${ }^{1}$ But, these problems arise, so to speak, within the framework of first generation rights.

Historically, first generation rights emerged as bourgeois society and markets displaced feudal relations. Second generation rights resulted from a later political mobilization, of the working class in Europe, expressed in social democratic parties of the late nineteenth century. Second generations rights are typically described as socio-economic rights, such as the right to education, housing, and the like - more generally, as rights to some degree of material well-being beyond that provided through the operation of market mechanisms of distributing material goods. Importantly, those market mechanisms are protected by first generation rights to property and liberty.

One way of grasping the distinction between first and second generation rights is the formulation in the 1937 Irish Constitution and the

${ }^{1}$ ANTONI ABAT Y NiNET AND MARK TUSHNET, THE ARAB SPRING: AN ESSAY ON

CONSTITUTIONALISM AND REVOLUTION (2015).

2 JOURNAL OF INSTITUTIONAL STUDIES 2 (2016) 
1949-50 Indian Constitution, which refer to second generation rights as directive principles of public policy, and attempt to insulate them from constitutional review, in contrast to the first generation rights, which the courts can enforce. ${ }^{2}$

Third generation rights are less well defined, having become embedded in national constitutions more recently. Historically, third generation rights, like first and second generation rights, are associated with the political mobilization of social groups. They include language rights, cultural rights, and most recently environmental rights, and the mobilized social groups were national minorities, colonized populations, and the modern environmental movement, with some overlap among these groups. This category might appear to be, and perhaps is, a grab bag of disparate rights, but I will suggest that they are conceptually related.

Some astute analysts have suggested that realizing second and third generation rights would require violations of first generation rights - or, perhaps less provocatively, would require redefining the content of first generation rights so that they could be accommodated within a framework recognizing second and third generation rights.

As to second generation rights, the arguments were made by Carl Schmitt and Robert Nozick. Schmitt regarded programmatic constitutions, as he called those with second generation rights, as inconsistent with the concept of constitutionalism as he u8nderstood it. As I understand his argument, it is that realizing second generation requires the constant readjustment of the outcomes of market processes. That readjustment, again as I understand Schmitt's argument, would destabilize expectations about how one can plan one's life to a degree incompatible with basic ideas about the rule of law. ${ }^{3}$ Further, writing in the 1920s, Schmitt may have thought that the first generation right to property could only be realized through a roughly libertarian system, in which readjusting market outcomes would impair - certainly through regulatory interventions but possibly through ordinary taxation constitutionally protected property rights.

Writing while in his libertarian period, Robert Nozick made an argument of the latter sort, famously writing that achieving the kind of

${ }^{2}$ As noted below, the Indian and German experiences suggest that it is possible to infuse second generation rights into some seemingly first generation rights - in India the right to life, and in Germany the rights to human dignity and to the free development of personality.

3 This theme was of course taken up by FRIEDRICH A. VON HAYEK, THE ROAD TO SERFDOM (1944).

2 JOURNAL OF INSTITUTIONAL STUDIES 2 (2016) 
patterned outcomes sought in second generation constitutional systems would require making unlawful "capitalist acts between consenting adults." ${ }^{4}$ Yet, such acts were exemplars of core protections of individual liberty (and as a result, of property) provided in first generation constitutions. An important feature of this argument, I believe, is that it rests on what I would call a "thin" libertarianism, committed (when we are thinking about constitutions) only to the very heart of individual liberty, the right of individuals with appropriate capacity ("adults") to make agreements of whatever content ("capitalist acts") with others, as long as the contracting parties' choices are fully informed (in part, a matter of capacity) and do not materially harm others. ${ }^{5}$

The argument that third generation rights can violate first generation ones is a reasonably common one among constitutional theorists. Typically, the argument focuses on cultural rights, which - because they are rights associated with traditional cultures - often would perpetuate the subordination of women in those cultures. Protecting cultural rights of such cultures would then impair the first generation right to civic equality. ${ }^{6}$ Third generation rights might conflict with or substantially impede the realization of second generation rights as well, for example in cases where protection of the culturally significant territories of indigenous peoples requires removing important natural resources - the sale of which would generate the wealth needed to realize second generation rights - from exploitation.

One might respond to these arguments - which, I observe, are offered as critiques of the idea that adopting second and third generation rights is a good thing - by noting (1) that libertarianism, either weak as in Nozick or strong as in Hayek, appears to be an important component of the arguments' definition of the content of first generation rights, and (2) that there are many versions of liberal constitutionalism that are not committed to even a weak libertarianism. The critical arguments, though, do seem to me to identify some real "conflicts" between second and third generation rights, on the one hand, and core first generation rights on the other. With respect to third generation cultural rights, for example, the

${ }^{4}$ ROBERT NOZICK, ANARCHY, STATE, AND UTOPIA (1974).

"I use the term "material harm" to rule out arguments that third parties could be harmed by the distribution of wealth that results from the contract. The term, for which others might be substituted, rules out envy as a proper ground for displacing the contracting parties' choices.

${ }^{6}$ BRIAN BARRY, CULTURE AND EQUALITY: AN EGALITARIAN CRITIQUE OF

MulticulturALiSM (2001), develops the argument in philosophical rather than purely constitutional terms.

2 JOURNAL OF INSTITUTIONAL STUDIES 2 (2016) 
argument seems rather strong that some male-preferring rules of governance and succession in minority cultures really are inconsistent with the first generation right of civic equality. ${ }^{7}$ With respect to second generation rights, the US experience with campaign finance regulation suggests the possibility that maintaining a political system that will sustain second generation rights might require restrictions on freedom of expression - roughly, the advocacy by plutocrats for policies that protect their interests and thereby make realization of second generation rights through political action more difficult or impossible - that would (properly) be regarded as violations of the right to free speech. ${ }^{8}$

There is an obvious response to arguments about conflicts among generations of rights. To present it I rely on Robert Alexy's argument that (constitutional) rights are subject to optimization or - in terms more conventional in US legal discourse - to mutual accommodation. A common example involves regulation of hate speech. Advocates of hate speech regulation say that such regulation advances the first generation right to civic equality, while its opponents say that such regulation violates the first generation right to freedom of speech. Alexy argues that constitutional systems (and their courts) should deal with these assertions by optimizing both civic equality and freedom of speech rather than by giving one priority over the other. ${ }^{9}$ Alexy's conceptualization offers a method of transforming apparent conflicts among first generation rights into specifications of those rights so that they do not conflict.

Could the optimization technique "work" just as well to eliminate the

${ }^{7}$ I note that that observation does not have any necessary implications for the determining the proper institutional response to the conflict, and in particular that the observation does not necessarily imply that a constitutional court in a nation with third generation rights should declare legally ineffective cultural practices inconsistent with first generation rights.

${ }^{8}$ The example is a complex one, because it incorporates institutional considerations that might be outside the scope of the claims about conflict versus consistency. Suppose that protecting rights of free expression does mean that plutocratic policies will prevail in ordinary politics, and that legislatures will not enact programs protecting second generation rights. At least in concept, constitutional courts could step in and enforce those rights directly (or, more likely, judicial intervention would change the contours of ordinary politics and offset some of the advantages the plutocrats have because their speech is constitutionally protected). Continuing the example would require some discussion of mechanisms of selection of judges on constitutional courts, which would take these comments too far afield.

${ }^{9}$ For present purposes it is irrelevant what conclusion one reaches on the optimization question, which might be quite sensitive to the particulars of the regulation at issue.

2 JOURNAL OF INSTITUTIONAL STUDIES 2 (2016) 
asserted conflicts among the generations of rights? The answer, unfortunately, may be, "Yes and no." Optimization operates on rights, which are a subset of interests - roughly, interests that are particularly important. ${ }^{10}$ Pit a right against an interest, and the right prevails unless there are exceptionally strong reasons for advancing the interest in the circumstances. ${ }^{11}$ Similarly when an optimized set of rights is pitted against an array of interests. The point here is that the optimization technique requires a distinction between rights and (mere) interests lest it be reduced to a simple "all things considered" judgment about what is good public policy and thereby eliminate constitutional rights qua rights from the analysis. ${ }^{12}$

If I am right about this, it becomes important to identify the set of constitutional rights on which the optimization technique operates. Again, the technique is: Optimize within the set of constitutional rights, then evaluate whether interests are sufficiently strong to overcome the optimized rights. We can now say that, with respect to constitutions that recognize only first generation rights, second and third generation "rights" are actually mere interests and, crucially, outside the scope of the optimization technique.

Unless we can fold second and third generation rights into the set of first generation rights. The Indian Supreme Court has done so by treating some second generation rights as comprehended within the right to life. Germany's Basic Law does something conceptually similar by recognizing a right to dignity and a right to full development of

${ }^{10}$ It is sometimes said that Alexy's approach does not require that we distinguish between rights and interests, or, as it is sometimes put, his approach eliminates the idea that rights are "trumps" over interests. To some extent, I believe that this argument rests on a misunderstanding of the idea of rights-as-trumps, which is not that rights always prevail over interests, but that they do so unless the interests are particularly important (in the circumstances). A similar error, in my view, is committed by those who criticize proportionality doctrine as treating all interests as the same, differing only in their weight in specific circumstances.

${ }^{11}$ As I suggest below, one might recharacterize interests under those circumstances as rights: When there are exceptionally strong reasons for advancing it, an interest becomes a right.

12 The case for special judicial attention to rights disappears, I believe, without a distinction between rights and interests, because the adjustment of competing interests is precisely what the ordinary - "legislative" - political process is about. 
personality. ${ }^{13}$ What these moves do is eliminate the distinctions among generations of rights, and in doing so they eliminate the possibility of conflicts among rights in the way that optimization eliminates conflicts within the standard set of first generation rights.

Yet, I think, the concerns underlying the claims about conflicts made by Schmitt, Barry, and others would persist. Instead of saying that second generation rights conflict with first generation ones, they would say that the optimization within the enhanced set of rights will sometimes produce results - and in particular a finding that some action is constitutionally permissible - different from the results reached by optimizing only the older set of rights, where the action in question would be constitutionally impermissible. We could no longer describe the action as a violation of rights, but it would still be undesirable (on these accounts).

In addition, eliminating the differences among the generations of rights by defining some first generation rights quite capaciously would obscure the underlying structure of the rights. As a first and quite imperfect cut, first generation rights are inherently individual, in the sense that (once properly specified through optimization) an individual's first generation rights can be implemented/protected without impairing anyone else's rights, whereas third generation rights are inherently collective, meaning that no individual can hold a cultural or language right by himself or herself because culture and language are inherently collective activities. In addition, first and third generation rights are rights against the state (or perhaps more accurately, against groups of people organized into political society). In contrast, second generation rights are rights against "the market," and in particular against the results of invisible hand processes not attributable to any individual or group of individuals except insofar as market structures are underwritten by law. These distinctions seem to me useful ones. For example, the qualification about markets being organized by law provides suggestions about how one ought to analyze questions about state action and horizontal effect. These distinctions would be blurred were we to treat all rights as falling within a single category, as the strategy of folding second and third generation rights into the right to life or to human dignity would have it.

Further, treating second and third generation rights as somehow implicit in one or another first generation right seems to resolve the apparent conflicts or tensions by a definitional trick. It seems to me notable that the German and Indian courts did so when second

${ }^{13}$ The Hartz IV decision invokes the right to dignity in finding unconstitutional part of a system of social provision.

2 JOURNAL OF INSTITUTIONAL STUDIES 2 (2016) 
generation rights had become embedded in many other constitutions and, importantly, when the political movements favoring second generation rights were strong in those nations. ${ }^{14}$ Their constitutional courts may have felt that realizing their nations' then constitutional values required recognition of second generation rights, but they faced recalcitrant constitutional texts and seized upon text referring to a first generation right as the vehicle for recognizing second generation rights. One might support this speculation by noting that the United States has not moved substantially in the direction of recognizing those rights, because of the combination of a recalcitrant text and the weakness of the social democratic movements that support those rights. But, the United States is constitutionally exceptional in so many ways that I would not place much weight on the particular example. Identifying a set of national constitutions that recognize only first generation rights and examining whether their constitutional courts make the same moves that the German and Indian courts have, and why or why not, would be useful, though I fear that the set is too small to generate anything more than speculation.

Suppose that I am right in thinking that there is at least a tension between first and subsequent generation rights, a tension that is greater than the tensions among first generation rights that are resolved by optimization. How might constitutional systems manage such tensions where, again, the technique of optimization is unavailable?

Two techniques, one a matter of institutional design and the other a matter of constitutional doctrine, come to mind. I developed the argument that weak or dialogic forms of constitutional review are particularly suitable for the enforcement of second generation rights..$^{15} \mathrm{I}$ did so on grounds internal to the structure of second generation rights, roughly that the enforcement of second generation rights poses problems of polycentricity. The argument may be adapted to the problem of tensions between second and first generation rights. My thought is that

${ }_{14}$ The German case is a complex one because social democratic movements were important in Germany from the late nineteenth century, but until the adoption of the Basic Law could find voice only in legislation, not in a constitutional court. After the Constitutional Court was created, Cold War pressures and the national commitment to a classical liberal economic program might have impeded giving constitutional grounding to second generation rights. I emphasize the speculative nature of this account.

${ }^{15}$ MARK TUSHNET, WEAK COURTS, StRONG RightS: JUdicial REVIEW AND SOCIAL WELFARE RightS IN COMPARATIVE CONSTITUTIONAL LAW (2008). 
optimization across generations of rights can be done, but will be done well only through the interaction between legislatures and constitutional courts. Adjusting customary inheritance practices to address questions of gender discrimination, for example, may be "quasi"-polycentric, for example, and accommodating national economic development to indigenous cultural practices seems to me clearly so. Notably, one important theme in constitutional developments with respect to the latter is that the participation of indigenous communities in planning for the use of local resources is often said to be constitutionally required, with the (complex) caveat that participation does not mean that the communities have a veto over development plans.

The doctrinal technique for accommodating first with later generation rights is proportionality. The idea is simple: Expand the set of rights to which proportionality analysis applies to include second and third generation rights, on a par with first generation rights and not as "mere" interests and not as interests that are somewhat important but not important enough to weigh heavily against an infringement of a first generation right.

Proportionality is a promising technique here, but using it would require significant elaborations of the doctrine beyond its current state. In my view, contemporary proportionality doctrine has real difficult in dealing with cases in which courts and scholars acknowledge that the interests promoted by infringements on rights are multiple or complex. ${ }^{16}$ A signal of the difficulty is Alexy's effort to identify broad categories of cases using the terms "high," medium," and "low," each along two dimensions, and then to discuss primarily cases in the "low-high" and "high-low" categories. My personal view is that even with respect to first generation rights proportionality doctrine requires substantial elaboration to deal with the "intermediate" cases, such as "medium-low" or "high-medium." Extending the doctrine to deal with second and third generation rights would perhaps propel that elaboration.

A final observation about both weak-form review and proportionality doctrine: The more expansive their scope is, the more likely it is that courts and scholars will come to think that those techniques are suitable for "core" first generation rights, which have so far been reasonably stably specified. Examples include strict constitutional regulation of (1) laws penalizing mere criticism of government policy (or penalizing such criticism on the ground that it has the potential to lead to defiance of

${ }^{16}$ For my elaboration of this point, see Mark Tushnet, Making Easy Cases Hard, in Mark Tushnet and Vicki Jackson (eds.), PROPORTIONALITY [full title to be determined] (2017, forthcoming).

2 JOURNAL OF INSTITUTIONAL STUDIES 2 (2016) 
existing law), (2) laws authorizing gender discrimination with respect to core political rights such as voting and speech, and (3) laws authorizing torture and similar practices. Proportionality doctrine does have the resources to deal with these questions, by treating some governmental goals as impermissible. ${ }^{17}$ Personally I have not been satisfied with the explanations offered for such exclusions, which seem to me either ad hoc or the result of some sort of implicit alternative, more categorical analysis that if exposed could serve as a substitute for proportionality analysis more broadly. Expanding proportionality analysis to include second and third generation rights - and so seeming to make it a truly comprehensive doctrine - might induce doctrinal development by bringing attention to these difficulties with the application of proportionality doctrine to core, well-specified constitutional rights.

Perhaps, then we can describe second and third generation rights as deepening our understanding of human rights, but not, I suggest, as deepening our understanding of first generation rights. Rather, they supplement first generation rights and, in some circumstances, their realization will require revision of our understanding of particular specifications of first generation rights.

\section{REFERENCES}

ANTONI AbAT Y Ninet AND MARK TUSHNET, THE ARAB SPRING: AN ESSAY ON CONSTITUTIONALISM AND REVOLUTION (2015).

BRIAN BARRY, CULTURE AND EQUALITY: AN EGALITARIAN CRITIQUE OF Multiculturalism (2001)

FRIEDRICH A. vON HAYEK, THE ROAD TO SERFDOM (1944).

Mark Tushnet, Making Easy Cases Hard, in Mark Tushnet and Vicki Jackson (eds.), PROPORTIONALITY [full title to be determined] (2017, forthcoming).

${ }^{17}$ I believe that this is the usual way to deal with laws authorizing torture, for example.

2 JOURNAL OF INSTITUTIONAL STUDIES 2 (2016) 
MARK Tushnet, WEAK COURTS, StRONG RightS: JUdicial REVIEW AND SOCIAL WELFARE RigHTS IN COMPARATIVE CONSTITUTIONAL LAW (2008).

ROBERT NOZICK, ANARCHY, STATE, AND UTOPIA (1974).

Notes on Some Aspects of the Taxonomy of "Generation" of Rights Notas sobre Alguns Aspectos da Taxonomia das "Gerações" de Direitos

Submitted: 2016-02-29 